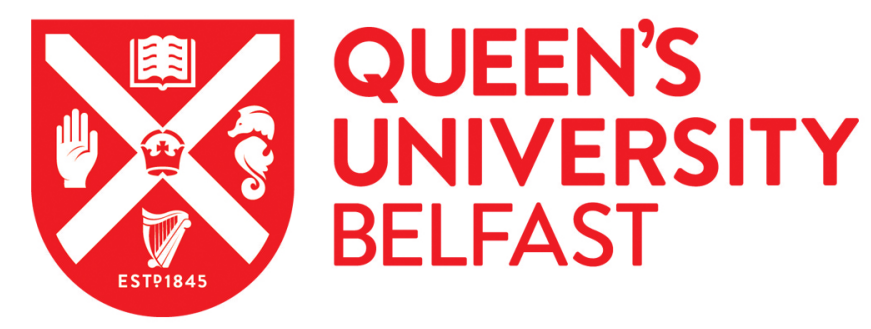

\title{
Multicharge Zwitterionic Molecules: Hydration, Kosmotropicity and Anti-fouling Potential
}

Level, G., Zhang, J., Brown, J., Hammond, O., Hannigan, B., Stella, L., Nockemann, P., \& Blesic, M. (2019). Multicharge Zwitterionic Molecules: Hydration, Kosmotropicity and Anti-fouling Potential. Journal of Colloid and Interface Science. https://doi.org/10.1016/j.jcis.2019.12.009

Published in:

Journal of Colloid and Interface Science

Document Version:

Peer reviewed version

Queen's University Belfast - Research Portal:

Link to publication record in Queen's University Belfast Research Portal

\section{Publisher rights}

Copyright 2019 Elsevier.

This manuscript is distributed under a Creative Commons Attribution-NonCommercial-NoDerivs License

(https://creativecommons.org/licenses/by-nc-nd/4.0/), which permits distribution and reproduction for non-commercial purposes, provided the author and source are cited.

\section{General rights}

Copyright for the publications made accessible via the Queen's University Belfast Research Portal is retained by the author(s) and / or other copyright owners and it is a condition of accessing these publications that users recognise and abide by the legal requirements associated with these rights.

Take down policy

The Research Portal is Queen's institutional repository that provides access to Queen's research output. Every effort has been made to ensure that content in the Research Portal does not infringe any person's rights, or applicable UK laws. If you discover content in the Research Portal that you believe breaches copyright or violates any law, please contact openaccess@qub.ac.uk. 


\title{
Multicharge Zwitterionic Molecules: Hydration, Kosmotropicity and
}

\author{
Anti-fouling Potential \\ Gaelle Level ${ }^{a}$, Jiaxin Zhang ${ }^{b}$, John Brown ${ }^{c}$, Oliver Hammond ${ }^{a}$, Brian Hannigan ${ }^{c}$, Lorenzo Stella ${ }^{b, c}$, \\ Peter Nockemann ${ }^{a}$, Marijana Blesic ${ }^{a *}$
}

\author{
${ }^{a}$ QUILL Research Centre, School of Chemistry and Chemical Engineering, Queen's University Belfast \\ Stranmillis Road, Belfast, BT9 5AG, UK, E-mail:m.blesic@qub.ac.uk \\ ${ }^{b}$ Atomistic Simulation Centre, School of Mathematics and Physics, \\ Queen's University Belfast, University Road, Belfast, BT7 1NN, UK \\ 'School of Chemistry and Chemical Engineering, Queen's University Belfast \\ Stranmillis Road, Belfast, BT9 5AG, UK
}

\begin{abstract}
This manuscript presents a comparative study of the physico-chemical behaviour of sulfobetaine-type single and double zwitterions and zwitterionic salts, and structurally similar mono-and di-cationic tetraalkylammonium salts in aqueous solutions. The study includes experimental determination of the density and viscosity of highly diluted aqueous solutions with derivation of the Jones-Dole viscosity Bcoefficient, partial molal volumes at infinite dilution, and hydration numbers. The study also examines the effects of addition of the salts on the surface tension of cationic and anionic surfactants, upper critical solution temperature of a non-ionic surfactant, solubility of amino acids, and stability of a protein. The experimental investigation was performed taking a broad bottom-up approach with the aim to elucidate the effect of molecular architecture and charge (two versus four) on the degree of surface hydration of a molecule, kosmotropicity, and interactions with charged and hydrophilic/hydrophobic surfaces - all-important characteristics which define ability of a functional group to resist protein attachment. The novel multicharged zwitterionic materials have exhibited superior qualities, thus paving the way to development of a new platform in design of hydrophilic and anti-fouling surfaces by employing the four-charge bearing molecular motifs.
\end{abstract}

Key words: aqueous solution, zwitterion, zwitterionic salt, tetraalkylammonium, surface tension, viscosity, density, Jones-Dole viscosity B-coefficient, protein, solubility, amino acid.

\section{Introduction}

Anti-fouling surfaces are a critical requirement for a wide range of biomedical applications including medical devices and biosensors,[1, 2] biotechnological separations and processing,[3] food[4] and maritime[5] industries. Unwanted protein adsorption can cause blood coagulation, inflammation, thrombosis, and failure of medical or processing devices, additionally, it can also lead to loss of activity of therapeutically formulated protein solutions.[3] Numerous ways exist for coating various substrates with layers that have controllable interaction with macromolecules (proteins), e.g. polyelectrolyte 
multilayer films and self-assembled monolayers bearing antifouling functional groups.[6] Polyethylene glycol - based (PEG) surfaces have been widely used as anti-fouling layers; this is primarily due to the strong hydration layer that arises from the $\mathrm{H}$-bonding between $\mathrm{PEG}$ and $\mathrm{H}_{2} \mathrm{O}$ that aids in preventing protein attachment. $[7,8]$ Recently, it was found that zwitterionic moieties such as sulfobetaines and carboxybetaines[9] provide high resistance towards protein adsorption, as the strong electrostatic interactions allow a higher level of hydration than those enabled by PEG surfaces[10]. Thus, zwitterion-functionalised polymers e.g. poly(sulfobetaine methacrylate), poly(carboxybetaine methacrylate), and poly(2-methacryloyloxyethyl phosphorylcholine) have been recognised as promising alternatives to PEG because of their higher chemical stability, relatively comparable effectiveness to resist biofouling, and improved long-term performances regarding specific proteins.[9-13]

It is scientifically evident that the key underlying phenomenon of surface resistance to non-specific protein adsorption is its strong surface hydration. $[8,14-16]$ Additionally, it has been recognised that "most of the known protein-resistant surfaces are based on displays of kosmotropes - molecules that stabilize the native structure of proteins".[17] Hence, this work will compare hydrophilicity and kosmotropicity of the molecules with already established antifouling performances, such as sulfobetaine zwitterions and tetraalkylammonium salts[7, 18], with structurally similar materials bearing four charged moieties in their molecule: zwitterionic salts, double zwitterions, and a dicationic tetraalkylammonium salt (Scheme 1.).

Zwitterionic Salts (ZWSs) are a distinctive category of ionic compounds, first introduced in 2017 by Blesic et al.[19] ZWSs contain an asymmetrically - distributed quartet of charges in forms $\left[A^{+} B^{-} Y^{+}\right]\left[X^{-}\right]$ or $\left[A^{+} B^{-} X^{-}\right]\left[Y^{+}\right]$. ZWSs exhibit enhanced charged surface area and theoretically stronger hydration, and it is therefore of significant practical interest to investigate the nature of the interaction between water and ZWSs and assess whether this could translate into improved resistance to protein adhesion. It has been also demonstrated that ZWSs are able to salt - out both non - polar and polar amide groups which indicates that ZWSs represent a group of protein stabilizers[20], thus meeting the second requirement for protein - resistant surfaces.<smiles>C[N+](C)(C)CCCS(=O)(=O)[O-]</smiles><smiles>CC[N+](C)(C)CC[N+](C)(C)C</smiles><smiles>C[N+](C)(C)[Mg][Mg]</smiles><smiles>CN(C)CCC[N+](C)(C)CCCS(=O)(=O)[O-]</smiles><smiles>[2H][N+](C)(C)CCN(C)CCCS(=O)(=O)[O-]</smiles>
$\mathrm{ZWS}$
$\mathrm{C}_{2} \mathrm{~S}: \mathrm{R}=\mathrm{CH}_{2} \mathrm{CH}_{3}$
$\mathrm{C}_{4} \mathrm{~S}: \mathrm{R}=\left(\mathrm{CH}_{2}\right)_{3} \mathrm{CH}_{3}$
$\mathrm{C}_{6} \mathrm{~S}: \mathrm{R}=\left(\mathrm{CH}_{2}\right)_{5} \mathrm{CH}_{3}$

Scheme 1. Structures and abbreviations of molecules synthesised and used in this work: ZW: 3(trimethylammonio)-1-propanesulfonate, DC: - $\mathrm{N}^{1}, \mathrm{~N}^{2}$-diethyl- $\mathrm{N}^{1}, \mathrm{~N}^{1}, \mathrm{~N}^{2}, \mathrm{~N}^{2}$-tetramethylethane-1,2diaminium bromide, TMAB - tetramethylammonium bromide, DS: 3,3'-[1,2- 
ethanediylbis(dimethylammonio)]di(1-propanesulfonate), ZWS - 3-((2-

(dimethyl(alkyl)ammonio)ethyl)dimethylammonio)1-propanesulfonate bromide.

This study has undertaken an exploratory bottom-up evaluation of the five salts and their potential as non - fouling functional groups, and it is organised into three sections: the first section aims to assess the hydration capacity of the synthesised molecules (structures and abbreviations are shown in the Scheme 1), the second section provides an insight into their kosmotropicity, and the final section studies their behaviour at interfaces and interaction with charged surfaces, amino acids, and a protein.

\section{Materials and Methods}

Starting material: $\mathrm{N}, \mathrm{N}, \mathrm{N}^{\prime}, \mathrm{N}^{\prime}$-Tetramethylethylenediamine (Sigma-Aldrich, 99\%), 1,3-propanesultone (Alfa Aesar, 99\%), bromoethane (Alfa Aesar, 97\%), 1-bromobutane (Sigma-Aldrich, 99\%), 1-bromohexane (Aldrich 98\%), DL-Phenylalanine (Acros Organics, 99\%), L-Tryptophan (Alfa Aesar, 99\%), myoglobin (salt-free, lyophilized, Sigma-Aldrich, 95-100\%), trimethylamine solution (34 wt. \%) in ethanol (Sigma-Aldrich), were used without further purification.

Synthesis: ZW and ZWSs were prepared according to previously - described literature routes.[20, 21] More details on syntheses and characterisation can be found in ESI.

DS was synthesised by mixing of $N, N, N^{\prime}, N^{\prime}$-tetramethylethylenediamine (1 mol eq.) and 1,3-propanesultone (2 mol eq.) with $50 \mathrm{ml}$ of methanol in a round-bottom flask placed in an ice bath (moderately exothermic reaction). The product was obtained as a white precipitate and it was recrystallised from a water / methanol mixture. DC was prepared in reaction of $N, N, N^{\prime}, N^{\prime}$-tetramethylethylenediamine (1 mol eq.) and bromoethane ( $2.2 \mathrm{~mol}$ eq.) in a small amount of methanol under reflux with stirring at $40^{\circ} \mathrm{C}$. The product was obtained as a white crystalline precipitate and it was filtered and washed with acetone. More details on synthesis and characterisation including ${ }^{1} \mathrm{H}$ NMR, ${ }^{13} \mathrm{C}$ NMR, elemental analysis, thermogravimetric analysis, differential scanning calorimetry, and mass spectroscopy can be found in ESI.

NMR spectroscopy. All NMR spectra were recorded on a Bruker Avance spectrometer DPX 300 at $27^{\circ} \mathrm{C}$, using deuterated water as solvent.

Mass spectrometry. ESMS measurements were carried out on a Waters LCT Premier instrument with an Advion TriVersa NanoMate injection system (cone voltage $50 \mathrm{~V}$, source $120^{\circ} \mathrm{C}$ ). Both positive and negative ions were detected, with an $\mathrm{m} / \mathrm{z}$ range of 50 to 1500 . Samples were injected as dilute solutions in acetonitrile.

Differential scanning calorimetry (DSC). The melting points of the synthesised materials were measured by a TA Instruments Q2000 DSC. Cooling was accomplished by using a refrigerated cooling system capable of controlling the temperature down to $220 \mathrm{~K}$. Dry nitrogen gas (flow rate of $c a .50 \mathrm{~cm}^{3} \mathrm{~min}^{-1}$ ) was purged through the DSC cell. For each sample, three scans were run with scan rates of $5{ }^{\circ} \mathrm{C} \mathrm{min}{ }^{-1}$.

Thermogravimetric analysis (TGA). Decomposition temperature measurements were performed in a TA Instruments Q5000 IR thermogravimetric analyser under flow of nitrogen. The measurements were done in platinum pans, at a heating rate of $10^{\circ} \mathrm{C} \mathrm{min}^{-1}$, in air. The onset of the weight loss in each thermogram was used as a measure of the decomposition temperature.

Measurement of solubility of salts: In a conical vial $200-300 \mathrm{mg}$ of a salt was accurately weighed using an analytical balance. It was followed by a very slow dropwise addition of water (drop per 15 min) under continuous stirring until the solid was completely dissolved in the added solvent.

Measurement of salt effect on aqueous solubility limit of amino acids: experiments were performed by equilibrating aqueous solutions containing $\mathrm{C}_{2} \mathrm{~S}, \mathrm{DS}$, and ZW with amino acid added in excess (L-tryptophan and DL-phenylalanine) overnight at room temperature. The excess of the solute was left to separate / precipitate and then centrifuged, and the aqueous phase was analysed by UV-vis spectroscopy. Agilent Technology Cary 60 UV-VIS spectrophotometer was used to determine the concentration of DL-phenylalanine and L-tryptophan. A $10 \mathrm{~mm}$ silica UV absorption cuvette was used in all measurements. Calibration curves were obtained by using 
series of solute dilutions in Millipore water. The absorbance was measured at the wavelength of $279 \mathrm{~nm}$ for Ltryptophan and $258 \mathrm{~nm}$ for DL-phenylalanine.

Measurement of stability of protein: Stock solution of myoglobin with concentration of $0.02 \mathrm{~g} \mathrm{dm}^{-3}$ was prepared in $0.05 \mathrm{M}$ phosphate buffer at $\mathrm{pH}$ 7.0. Solutions of salts $\left(\mathrm{C}_{2} \mathrm{~S}\right.$, DS, and $\mathrm{ZW}$ ) were prepared gravimetrically in concentrations $0.01-0.05 \mathrm{M}$ and mixed with an equivalent volume of protein solution. Absorbance of the prepared solutions was measured using the UV-VIS instrument previously described.

Viscosity measurements: The kinematic viscosities of the solutions were measured using a micro Ubbelohde capillary viscometers equipped with a ViscoClock plus electronic timing unit (SI Analytics GmbH, Mainz, Germany) at $30^{\circ} \mathrm{C}$. The instrument was immersed in a thermostatic water bath with temperature controlled within $\pm 0.02 \mathrm{~K}$. For every solution the kinematic viscosity was measured at least ten times and an average value was reported. The time constants of the instrument $A$ and $B$ from the relation $v=A / t-B / t^{2}(t-$ flow time (s), $v$ - kinematic viscosity $\left.\left(\mathrm{m}^{2} \mathrm{~s}^{-1}\right)\right)$ were calculated by calibrating the instrument with water at $30^{\circ} \mathrm{C}$ and $40^{\circ} \mathrm{C}$. Dynamic viscosity of solution was calculated from density and kinematic viscosity data from the relation $\mu=\rho$. $v$, where $\mu$ is dynamic viscosity (Pa s), $\rho$ is density of solution $\left(\mathrm{kg} \mathrm{m}^{-3}\right)$, and $v$ is kinematic viscosity $\left(\mathrm{m}^{2} \mathrm{~s}^{-1}\right)$. The estimated uncertainty of the viscosity measurement was $\pm 0.05 \mathrm{mPa}$.

Liquid-liquid equilibria: All cloud-point determinations on the temperature - composition liquid - liquid phase diagrams at a nominal pressure of $0.1 \mathrm{MPa}$ were performed using a dynamic method with visual detection of the solution turbidity. For this purpose, Pyrex glass view cell with magnetic stirring was used. Samples were gravimetrically prepared directly inside the cell using an analytical balance. The cell was then immersed in a thermostatic bath. Under continuous stirring, the two or three heating runs were performed for each sample, with the rate of temperature change near the cloud point not exceeding $5 \mathrm{~K} \mathrm{~h}^{-1}$. Starting in the homogeneous region, upon heating, the temperature at which the first sign of turbidity appeared was taken as the temperature of the liquid - liquid phase transition.

Density meter: Density measurements were performed using Anton Paar DMA 4500 M oscillating tube density meter with repeatability of density of $1 \cdot 10^{-5} \mathrm{~g} \mathrm{~cm}^{3}$, and temperature stability of $0.01{ }^{\circ} \mathrm{C}$. The instrument was cleaned using water and acetone and dried using dehumidified air prior to any measurements.

Surface tension measurements: Surface tension of aqueous solutions was measured with the drop shape analysis method, using a calibrated DSA25 instrument from Krüss GmbH equipped with Krüss ADVANCE software. Droplets of the relevant solution were suspended from a blunt-tipped 13 Gauge needle and the surface tension reported as an average of at least 10 measurements. For each individual measurement the dimensions of the drop were captured and fitted using the Young-Laplace equation. Measurements were conducted at room temperature without explicit control.

Crystallography: Single crystals of DS and DC were measured on an Agilent SuperNova, Dual, Cu, EosS2 diffractometer. The crystal was kept at $100 \mathrm{~K}$ during data collection. Using Olex2 8, the structure was solved with the SheIXT 9 structure solution program using Intrinsic Phasing and refined with the ShelXL9 refinement package using Least Squares minimisation.

\section{Results and Discussion}

\section{Hydration}

The ability of a coating to resist protein attachment depends on the hydration capacity of the functional groups present on its surface and the surface packing. To date, literature reports were focused only on a limited number of non - fouling functional groups that displayed strong surface hydration, mainly based on PEG and two-charge zwitterions consisting of ammonium and either phosphate, sulfonate, or carboxylate groups. In this study, we investigated whether incorporating additional charges in a molecular structure can improve hydration capacity, thus potentially making these new four - charge structures more effective non-fouling groups. We have synthesised three four - charge quaternary ammonium - type structures, namely, di-cation (DC), di-zwitterion (DS), and zwitterionic salt (ZWS: $\mathrm{C}_{2} \mathrm{~S}, \mathrm{C}_{4} \mathrm{~S}$, or $\mathrm{C}_{6} \mathrm{~S}$ ), and compared their physico-chemical behaviour with tetramethylammonium bromide (TMAB) and sulfobetaine zwitterion (ZW) (Scheme 1.). All synthesised compounds (ZWSS, DC, DS, and ZW) and commercially available TMAB were obtained 
either as white crystalline solids or amorphous powders which can be crystallised using anti-solvent crystallisation.

The crystal structures of DS, DC, and ZWS $\left(C_{2} S\right)$ are shown in Fig. 2. It was found that both $C_{2} S$ and DS crystallise with 3 and 2 molecules of water in a crystal unit, respectively, where hydrogen bonds were established between the oxygen atoms of the sulfonate group and the hydrogen atom of water. Additionally, $\mathrm{C}_{2} \mathrm{~S}$ forms weak $\mathrm{H}$-bonds between water oxygen atoms and the proton on the ammonium methyl groups, and with the bromide anion, thus indicating a strong water affinity which is also reflected in its high water solubility (see Table 1 ).
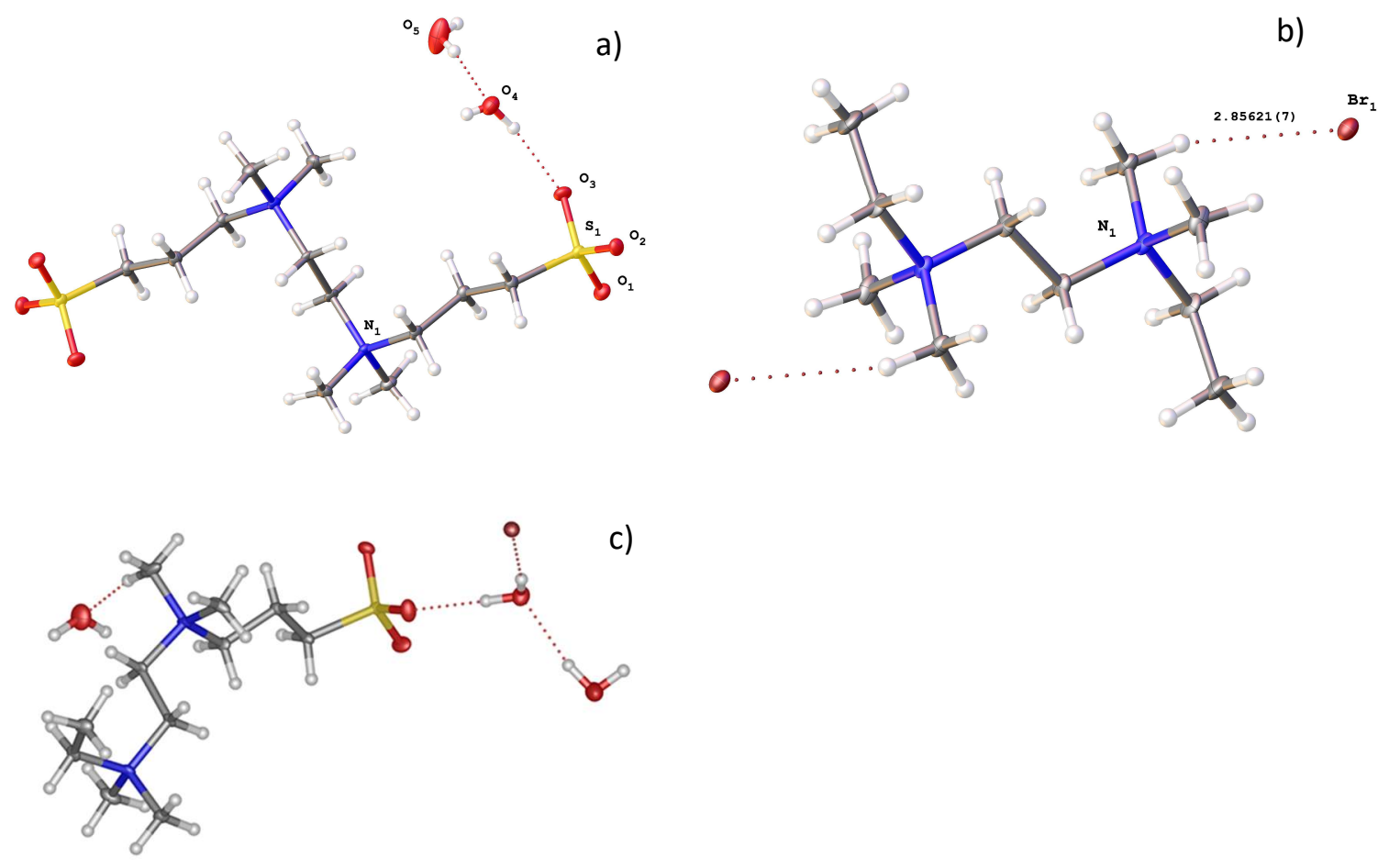

c)

Figure 2. Crystal structures of a) DS, b) DC, and c) ZWS $\left(C_{2} S\right)[19]$.

Table 1. Solubility in water, $S$, van der Waals molar volume, $V_{v d w}$, standard partial molal volume at infinite dilution, $V^{\infty}$, number of water molecule hydrated salt, $N_{H}$.

\begin{tabular}{|c|c|c|c|c|}
\hline compound & $S, \% w^{a}$ & $V_{v d W}, \mathrm{ml} \mathrm{mol}^{-1 b}$ & $V^{\infty}, \mathrm{ml} \mathrm{mol}^{-1}$ & $N_{H}$ \\
\hline ZW & 64.6 & 101.46 & 135.9 & 14 \\
\hline DC & 69.2 & 162.86 & 218.9 & 22 \\
\hline $\mathrm{C}_{2} \mathrm{~S}$ & 75.2 & 179.63 & 234.5 & 27 \\
\hline DS & 51.3 & 194.63 & 239.9 & 34 \\
\hline
\end{tabular}

${ }^{a}$ We estimate that the error associated with this measurement can be $\pm 2 \%$ because of the possibility of formation of a supersaturated solution. ${ }^{b}$ van der Waals volumes were calculated using the 'spacefill' program provided with the 'Tinker' software.[22]

Table 1. reports on the aqueous solubility of the studied compounds, expressed as the maximum amount of a solute that could be dissolved in water at room temperature $\left(25^{\circ} \mathrm{C}\right)$ and atmospheric pressure. The solubility follows the order $\mathrm{C}_{2} \mathrm{~S}>\mathrm{DC}>\mathrm{ZW}>\mathrm{DS}$. Besides the obvious practical importance of the aqueous solubility data, they also can be correlated to degree of hydration and lattice energies. In general, small ions with high surface charge show strong ion - dipole interactions in aqueous solution and a high degree of hydration, which is manifested in high aqueous solubility.[23] However, the aqueous solubility of dissolved ionic materials decreases as lattice energy increases, as seen in the case of solubility of sodium halides (solubility of $\mathrm{Nal}$ is $12.32 \mathrm{~mol} \mathrm{~kg}^{-1}$ and $\mathrm{NaF}$ is $0.985 \mathrm{~mol} \mathrm{~kg}^{-1}$ )[24]. 
The solubility process becomes more complex if dissolved material can engage in multiple interactions with the solvent, such as hydrogen-bonding.[23] The highest solubility is observed for the ZWS $\left(C_{2} S\right)$, which is a manifestation of the difference in the degree of hydration of the bulky cation and the monoatomic anion, as well as the hydrogen bond acceptor - donor ability of the molecule. The trend in aqueous solubility can also be interpreted by applying Law of Matching Water Affinities proposed by Collins, who suggested that only oppositely charged ions with matching free energy of hydration or surface charge density (i.e. size for equally charged ions) will spontaneously associate and form ion - pairs (such as $\mathrm{NaF}$ ), while dissociation and high aqueous solubility can be expected for oppositely charged ions with vastly different surface charge density.[25-27] In case of polyatomic molecules such as $\mathrm{C}_{2} \mathrm{~S}, \mathrm{Br}$ anion is weakly bound in the crystal structure, as may be expected, and easily accessible for hydration by water dipole (Fig. 1C). Thus, the strongly hydrated $\mathrm{Br}$ anion and the bulky and less hydrated cation stay separated by the water layer, as it is energetically more favourable than the process of forming an inner sphere ion pair by dehydration of bromide. Marginally lower, but still high solubility of DC and ZW can also be explained by the difference in anion - cation surface charge density, hydrogen bonding between negatively charged oxygen atoms of sulfonate group and water hydrogen, and broadly distributed surface charge in the cation which weakens the lattice strength.

Bockris et al. defined the primary hydration number as "the number of water molecules which are attached to the ion for a sufficiently long time so that they move with the ion from a given position in the solution to its next site".[28] For many decades, numerous experimental techniques have been used for the determination of hydration number, such as ionic mobility, ionic entropy, compressibility, solution density, Raman and infra-red spectroscopies, neutron and $x$-ray diffractions, and nuclearmagnetic resonance.[27-31] Simulation studies have shown that bound water in the primary hydration shell contributes to $95 \%$ of the repulsion between a surface and protein, thus emphasising the importance of determining the magnitude of hydration for the assessment of non - fouling ability of a functional group or a molecule.[8] In this work, we investigated the degree of hydration of the studied salts analysing the change of solution density as a function of solute (salt) concentration. Density measurements of aqueous solutions of all studied compounds were performed at a temperature of $25^{\circ} \mathrm{C}$ in a highly diluted regime within which solute - solute interactions are negligible (Fig. S1, ESI). The experimentally obtained solution density data as a function of solute concentration were used to determine the apparent molal volume of the solute, using the following equation for a twocomponent mixture:

$$
V_{\varphi}=\frac{M_{w}}{\rho}+\frac{10^{3}\left(\rho_{0}-\rho\right)}{m \rho \rho_{0}}
$$

where $M_{w}$ is the molecular weight of a dissolved solute $\left(\mathrm{g} \mathrm{mol}^{-1}\right), \rho$ is solution density $\left(\mathrm{kg} \mathrm{m}^{-3}\right), \rho_{o}$ is the density of water $\left(\mathrm{kg} \mathrm{m}^{-3}\right)$, and $m$ is the molality of solution $\left(\mathrm{mol} \mathrm{kg}^{-1}\right)$.[32] The obtained results are shown in Fig. 3. Large positive slopes were obtained for DS, DC, and $C_{2} S$, while lesser slopes were found for ZW and TMAB. The large gradient is demonstrative of strong salt - water interaction. 


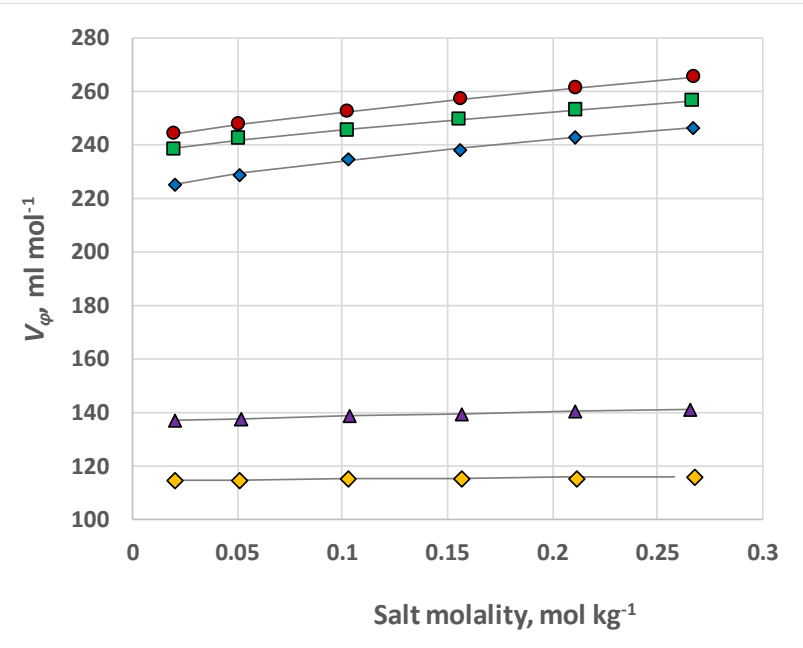

Figure 3. Experimental data (markers) and fits (lines) present dependence of apparent molal volume, $V_{\varphi}$, on concentration of $(\bullet) \mathrm{DS},(\square) \mathrm{C}_{2} \mathrm{~S},(\diamond) \mathrm{DC},(\Delta) \mathrm{ZW}$, and $(\diamond) \mathrm{TMAB}$ in aqueous solution at $25^{\circ} \mathrm{C}$.

In highly diluted solutions, the values of apparent molal volumes do not depend on concentration and they converge to standard partial molal volumes. Extrapolation of apparent molal volumes data was carried out using the Redlich and Mayer equation,[33] in order to produce values of limiting apparent molal volume of the salts at infinite dilution which are equal to standard partial molal volumes, $V^{\infty}$ :

$$
V_{\varphi}=V^{\infty}+S_{v} \sqrt{m}+B_{v} m
$$

where $V^{\infty}$ is the standard partial molal volume, $m$ molality, and $S_{v}$ and $B_{v}$ are fitting parameters.[34] The obtained standard partial volumes at infinite dilution for the studied salts are shown in Table 1. Determination of the value of the partial molal volume of a solute at infinite dilution provides a way to estimate the degree of surface hydration of the dissolved solute.[35, 36] Partial molal volume can be presented as the sum of intrinsic partial molal volume, $V_{\text {int }}^{\infty}$, and electrostriction partial molal volume which includes contributions arising from hydration, $V_{\text {elect }}^{\infty}$.

$$
V^{\infty}=V_{\text {int }}^{\infty}+V_{\text {elect }}^{\infty}
$$

$V_{\text {int }}^{\infty}$ can be estimated from van der Waals volume and packing density. [37] It was reported that packing density of organic solutes in water is $0.57-0.59$. Assuming that the value of 0.57 can be applied for the studied salts, gives the expression for calculation of $V_{\text {int }}^{\infty}$ :

$$
V_{\text {int }}^{\infty}=\frac{V_{v d W}^{\infty}}{0.57}
$$

Since the packing density of organic salts can vary [36] and their experimental values for the compounds used in this study are unknown, it is expected that relatively small errors could be associated with this approach; however, the trend among the studied molecules will not be significantly affected.

The electrostriction term represents the change of volume undergone by the solvent in the process of solute dissolution and hydration [34, 38] and can be used to estimate the number of water molecules hydrating a salt molecule, $N_{H}$, using the equation suggested by Millero[36]:

$$
V_{\text {elect }}^{\infty}=N_{H}\left(V_{e}^{\infty}-V_{b}^{\infty}\right)
$$

where $V_{e}^{\infty}$ is the molar volume of electrostricted water and $V_{b}^{\infty}$ is the molar volume of the bulk water.[36]

By assuming that the value of $\left(V_{e}^{\infty}-V_{b}^{\infty}\right) \approx 3.0 \frac{\mathrm{ml}}{\mathrm{mol}}$ proposed for electrolyte solutions[39] and amino acids[36] can be applied for the studied salts, we obtain the values of hydration number of the studied salts as given in the Table 1. Although the partial molal volume method often underestimates the extent of primary hydration number, it provides a satisfactory comparison of hydration numbers 
for a set of molecules when the same procedure is being followed. The reported values of hydration numbers of DS and ZWS molecules confirm that these materials can provide the highest hydration capacity of a surface if used as functional groups or terminal group of self-assembly monolayers for a certain packing density.

\section{Kosmotropicity}

The kosmotropicity of ions dissolved in a protein solution or attached to a surface affects protein stability, folding, biological activity, salting-in and salting-out phenomena, and consequently, processes of protein purification, crystallisation, and surface adsorption.[40] Ionic kosmotropicity is closely correlated to several thermodynamic quantities, such as Gibbs free energy, enthalpy and entropy of hydration, and partial molar volume. It can be quantified by determination of the Jones Dole viscosity coefficient, known as the B - coefficient.[41] The B - coefficient provides information on ion solvation and its magnitude directly expresses the dependence of relative viscosity of an electrolyte solution as a function of the electrolyte concentration.[42-44] In general, positive values of the B-coefficent indicate strong hydration and kosmotropic character of a dissolved electrolyte, while negative values are usually found in solutions of weakly hydrated, chaotropic salts. Small ions with high charge density are considered the most commonly kosmotropic and highly hydrated. However, bulky tetraalkylammonium cations also display high B-coefficient values because of the contribution arising from hydrophobic hydration. $[44,45]$ Qualitatively, it can be considered that the magnitude of the B-coefficent reflects the extent of hydration.

Table 2. Experimentally measured values of the Jones - Dole $B$ - coefficient for TMAB, ZW, DC, $C_{2} S$, and DS; reduction of critical micelle concentration (CMC) of SDS and DTMAB in the presence of $10 \mathrm{mM}$ of each salt.

\begin{tabular}{|l|c|c|c|}
\hline compound & B-coefficient & $\begin{array}{c}\text { SDS CMC } \\
\text { Reduction }(\mathrm{mM})\end{array}$ & $\begin{array}{c}\text { DTMAB CMC } \\
\text { Reduction }(\mathrm{mM})\end{array}$ \\
\hline TMAB & - & 7.1 & 3 \\
\hline ZW & 0.274 & 2.8 & 0.5 \\
\hline DC & 0.527 & 9.7 & 6 \\
\hline C 2 S & 0.706 & 8.6 & 2.8 \\
\hline DS & 0.772 & 2.9 & 2 \\
\hline
\end{tabular}

B-coefficients for the studied materials were obtained by fitting of the concentration dependence of dynamic viscosity using a derived form of the Jones-Dole equation[42]:

$$
\frac{\mu}{\mu_{0}}=1+A \sqrt{c}+B c
$$

where $\mu$ and $\mu_{0}$ are dynamic viscosity of solution and solvent (water), respectively, and $c$ is molar concentration of solute. The experimentally obtained values of $B$ - coefficient are presented in Table 2. The kosmotropicity decreases in the order $D S>C_{2} S>D C>Z W$, mirroring the hydration number trend. This confirms the hypothesis that four - charge molecules have an extended hydrated surface when compared to smaller molecules with fewer charged sites, providing a potential to prevent proteins attachment to a functionalised surface. It is noteworthy that the values of B - coefficient are high and close to those found in systems with imidazolium based ionic liquids with 6 or 8 methylene groups in the alkyl side chain[46] implying that ZWS are stronger kosmotopes and consequently more efficient phase splitting agents in aqueous - biphasic systems than short-chain ionic liquids as experimentally confirmed by Mills et al.[47]

Interactions with charged interfaces, amino-acids, and protein 
In order to understand the interactions of the studied salts with positively and negatively charged surfaces, which represent an ultimate simplification of charged patches of protein responsible for protein adhesion to a surface, we have studied the effect of addition of the salts on micellization of an anionic surfactant, sodium dodecyl sulfate (SDS), and a cationic surfactant, dodecyltrimethyl ammonium bromide (DTMAB). However, before analysis of the effect of the salts on aggregation of a surfactant it was necessary to understand the effect of the pure salts on the surface tension of water. The effect of inorganic and organic salts on the surface tension of water was broadly investigated both experimentally and via the utilisation of molecular simulation.[48] Almost all inorganic salts with monovalent and divalent cations,[48] guanidinium chloride, and urea increase the surface tension of aqueous solution typically up to $82 \mathrm{mN} \mathrm{m}^{-1}$ at high concentration range (4-7 M).[49] On the contrary, some salts consisting of organic ions, such as an tetraalkylammonium chloride, are known to decrease the surface tension of water.[50] Measurement of surface tension of aqueous solutions of the studied salts revealed that all salts lowered the surface tension of water (Fig. S3, ESI). However, the effect is mild, and in a low concentration regime $(<0.1 \mathrm{M})$ the salts cause a negligible contribution to surface tension decrease recorded in the studied surfactant solutions.

While it was expected that all studied salts will greatly affect the aggregation of negatively charged SDS micelle, it was also desirable to study also the effect of the salts on micellization of cationic DTMAB, as a proxy for cationic protein residues. It is well known that upon addition of salts to aqueous surfactant solution, formation of micelles (and possible vesicles at higher concentration[51]) will be dictated by a delicate balance of van der Waals forces between alkyl chains and the complex electrostatic interactions between monomers' charged heads and electrostatic double layer which comprises surfactant counterions and the added salt.[51] Samples with different concentrations of added salt were analysed by measurement of surface tension of aqueous solutions of the surfactants. Initially, the effect of concentration of added $\mathrm{C}_{2} S$ on CMC of SDS and DTMAB was investigated, showing that $5-10 \mathrm{mM}$ of $\mathrm{C}_{2} \mathrm{~S}$ is the optimum concentration range for these measurements, as the salt effect reaches a saturation and any further increase of salt concentration does not make a significant difference on micellization of the surfactants (Fig. S4, ESI).

Although this study was primarily interested in the performances of salts possessing the most hydrophilic character, we have also screened the effect of addition of two bulky and amphiphilic ZWSs, $\mathrm{C}_{4} \mathrm{~S}$ and $\mathrm{C}_{6} \mathrm{~S}$, on aggregation of SDS and DTMAB. Literature data has shown that contrary to small kosmotropic ions which do not bind to the micelle and stay at the micelle interface, bulky organic salts are prone to adsorption at the micelle surface or to ion - pairing with monomers often leading to aggregate growth, formation of bilayer structures, and precipitation. $[52,53]$ It was found that $C_{2} S$ and $\mathrm{C}_{4} \mathrm{~S}$ practically do not interact with DTMAB aggregates and have no effect on its micellization. A very mild decrease of CMC of DTMAB was observed in solution of $\mathrm{C}_{6} \mathrm{~S}$; this was a result of the simultaneous charge screening effect and enhanced van der Waals interaction between monomers and the hexyl chain of $\mathrm{C}_{6} \mathrm{~S}$ (Fig. S5, ESI). The effect of ZWSs on aggregation of anionic surfactant, SDS, was much more pronounced. The presence of two cationic groups in ZWS molecules led to their adsorption at the negatively charged micelle interface, thus strongly diminishing repulsion between sulfate groups. These electrostatic effects significantly facilitated the formation of surfactant monolayer at the airwater interface and micellization at higher SDS concentrations upon addition of $\mathrm{C}_{2} \mathrm{~S}$ and $\mathrm{C}_{4} \mathrm{~S}$ (Fig. $2 \mathrm{~S}$, ESI). In the case of amphiphilic $\mathrm{C}_{6} \mathrm{~S}$ the synergistic effect of van der Waals and electrostatic contributions led to a pronounced ion - pairing which resulted in precipitation within the concentration range 0.4-1.2 $\mathrm{mM}$ of SDS.

Table 2. and Fig. S6 ESI report the effect of DC, DS, and $\mathrm{C}_{2} \mathrm{~S}$ (salts bearing four charges) on the aggregation of the surfactants and compare their behaviour to the behaviour of their constituent units, two - charge ZW and TMAB. 
According to their ability to decrease CMC of DTMAB the salts can be ranked as: $D C>C_{2} S>T M A B>$ $D S>Z W$. The effect is generally weak but is slightly more pronounced for the salts containing the $\mathrm{Br}$ anion. It is believed that the increased concentration of $\mathrm{Br}$ counterions surrounding cationic polar heads decrease electrostatic repulsion, thus promoting aggregation of the surfactant. For SDS, the same ranking was observed with a much more pronounced reduction in $\mathrm{CMC}$ with the electrostatic attraction between quaternary ammonium cations and SDS sulfate groups acting to promote aggregation. The magnitude of this effect was remarkable higher for DC than for any other studied salt. Our hypothesis is that DC has a suitable geometry for an efficient charge screening process, where two quaternary ammonium cations and two ethyl groups surround the negatively charged sulfate groups in a staple-like configuration, thus contributing to minimising their mutual repulsion and promoting a denser packing, as shown by the significant reduction in the limiting surface tension above the CMC in the presence of DC (Fig. S6).

From this analysis of the interactions of the studied salts with charged interfaces, it can be concluded that salts containing a quaternary ammonium cation within a zwitterionic molecule, such as ZW and DS, practically do not interact with either positively or negatively charged surfaces. The salts containing quaternary ammonium cation(s) and anions as separate moieties, such as ZWS or DC, adhere to negatively charged surfaces; from the perspective of their application for protein resistant surfaces, it means that it is necessary to create mixtures with an oppositely - charged counterpart to keep a net neutral surface charge, as achieved in protein - resistant self - assembled monolayers consisting of alkyl $\mathrm{N}\left(\mathrm{CH}_{3}\right)_{3}{ }^{+}$and sulfate groups.[18] The results have also shown a powerful ability of DC to promote surfactant aggregation, which is important in processes where an ultra-low surface tension is required such as in the formation of $\mathrm{scCO}_{2}$ in water microemulsions.[54]

Considering the data presented in Table 1 on $\mathrm{CMC}$ reduction upon addition of salts, it might be tempting to conclude that the character and solution behaviour of ZWSs, particularly in the case of short chain $\mathrm{C}_{2} \mathrm{~S}$, is mainly determined by their "salt" nature, i.e. by presence of ionic groups, quaternary ammonium and bromide, making them similar to simple TMAB salt. However, such behaviour is manifested only in their interaction with ionic species. It was found that the behaviour of these hybrid materials with non - ionic and apolar compounds is defined by joint contributions coming from both the zwitterionic and ionic parts of a molecule. We have measured the effect of addition of TMAB, ZW, DS, and $\mathrm{C}_{2} \mathrm{~S}$ on lower critical solution temperature (LCST) of a non-ionic surfactant, Triton $\mathrm{X} 100$, in mixture with water at 0.003 molar fraction (0.097 mass fraction), as shown in Fig. 4. TMAB has shown a very weak ability to reduce the LCST of the studied surfactant, whereas ZW was a surprisingly effective salting - out agent. Interestingly, the results obtained for $\mathrm{C}_{2} \mathrm{~S}$ showed that its salting - out strength can be approximated as an additive effect which originates from the zwitterionic and the ionic parts of the molecule. Similarly, for DS the effect on promoting phase separation in the studied system seems to be an additive effect arising from the two ZW subunits of the molecules. 


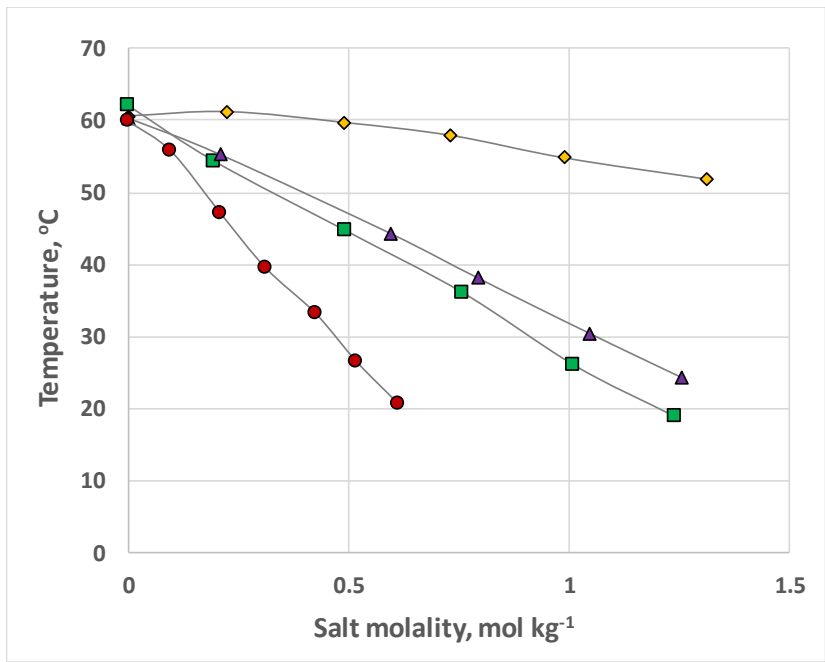

Figure 4. Effect of adding of $(\diamond)$ TMAB, $(\Delta) Z W,(\square) C_{2} S$, and $(\bullet)$ DS on the reduction of LCST of Triton X100

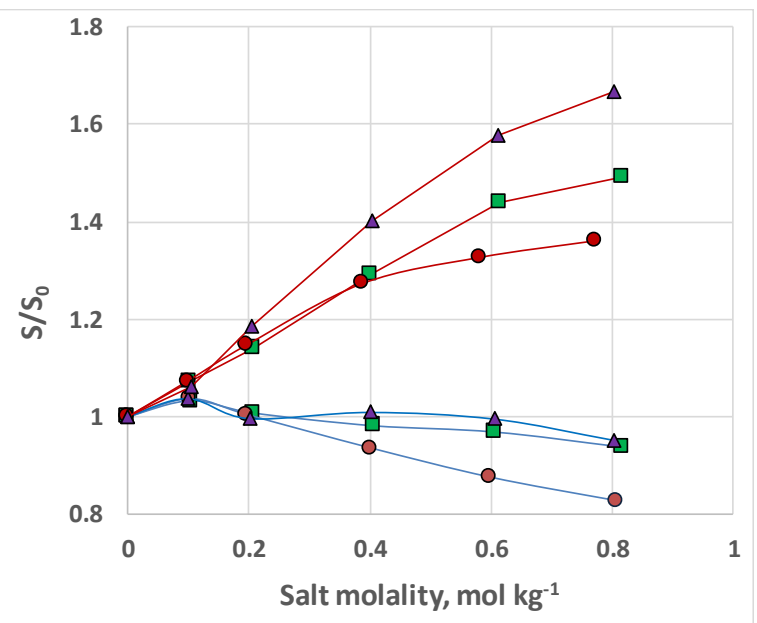

Figure 5. Changes in the solubility of DL-phenylalanine (blue line) and L-tryptophan (red line) in aqueous solution as a function of concentration of $(\Delta) Z W,(\square) C_{2} S$, and $(\bullet)$ DS expressed through a ratio of the amino acid solubility in the salt containing aqueous solution (S) and in pure water (So).

Finally, we have studied the influence of these salts on the behaviour of the amino acids, L-tryptophan and DL-phenylalanine, and the protein myoglobin in aqueous solution. Phenylalanine contains a phenyl ring and can be considered a hydrophobic amino acid. The rationale for studying the behaviour of the hydrophobic phenylalanine in presence the of the salts stems from the fact that around $57 \%$ of monomeric protein surface is nonpolar.[55] Conversely, L-tryptophan is an amphipathic amino acid due to the presence of nitrogen atoms in the aromatic ring which form hydrogen bonds with water.[56] Because of its amphipathic nature tryptophan is typically located at the aqueous interface in the exterior portion of a protein, and consequently in close proximity with salt containing media. Although understanding amino acid - salt interaction has broad important implications, it would be an oversimplification to extrapolate insights into interactions between proteins and the studied salts from the behaviour of simple amino acids. The effect of the ionic strength of media and nature of the salts on solubility of the amino acids, L-tryptophan and DL-phenylalanine, in the aqueous solution of $\mathrm{C}_{2} \mathrm{~S}, \mathrm{DS}$, and ZW is presented in Fig. 5 . It was found that the studied salts preferentially salt-out DL- 
phenylalanine. On the other hand, a surprisingly strong attractive interaction and salting-in effect was observed in solutions of L-tryptophan which is manifested in an increase of the amino acid aqueous solubility by up to $70 \%$. In that sense, it is interesting to notice that the highest increase of solubility of L-tryptophan was found in solution of ZW, which is usually considered a protein stabiliser and an efficient protein - repelling group. The results are important because they also provide an explanation why significantly higher distribution coefficients of L-tryptophan compared to DL-phenylalanine were observed in aqueous biphasic systems consisting of ZWSs.[47] These results also raise questions about the reasons for differential interactions between ZWSs and aromatic molecules, with very strong attractive interactions observed for phenol[20] and tryptophan, and repulsion for DL-phenylalanine. More powerful instrumental techniques, such as neutron-scattering are required to shed some light on the chemical mechanisms responsible for the observed interactions.

In order to get a better insight on any protein - repelling and stabilising, or protein - interacting and destabilising propensity of the salts, the stability of myoglobin was examined for the various salts as a function of ionic strength. Myoglobin is a water soluble protein consisting of 150 amino acids and it is often used as a model protein for studying the process of protein unfolding.[57] The heme group of myoglobin contains an iron atom and porphyrin, and is responsible for protein stability.[58] When the protein is in a stable, native state the heme gives a sharp absorption band at $409 \mathrm{~nm}$. The process of protein destabilisation is often associated with increasing water solubility of the hydrophobic parts of amino acid in the protein core responsible for stability of the tertiary structure of the protein. [59] The destabilising of myoglobin happens when the heme is exposed to the aqueous environment and is followed by a decrease of absorbance intensity at $409 \mathrm{~nm}$.[60] No spectroscopic variance was observed in this region for myoglobin in the aqueous solutions of $Z W, C_{2} S$, and DS within a salt concentration range of $10-50 \mathrm{mM}$ (Fig. S7 (ESI)). This result is not surprising as it was also reported that myoglobin remains stable in the presence of hydrophilic imidazolium based ionic liquids containing $\mathrm{Br}$ or $\mathrm{Cl}$ anions.[61, 62]

\section{Conclusions}

The study has established that the four - charge molecules, ZWS and DS, possess the highest hydration capacity and kosmotropicity. DS has shown no notable interactions either with positively or negatively charged surfaces, studied here in the form of cationic and anionic micellar interfaces. ZWSs are effectively inert in the presence of positively charged surfaces yet adsorbed to negatively charged surfaces. Therefore, from perspective of an application where contact with negatively charged protein is anticipated, it would be necessary to be used in a mixture with oppositely charged analogue with the same number of charges. All studied molecules in their mixtures with myoglobin acted as protein stabilizers. The current experimental findings suggest that these novel multi - charge zwitterionic materials possess superior hydrophilicity and kosmotropicity over simple two-charge molecules, [63, 64] highlighting these structures as ideal to be tested and employed as functional groups in the design of advanced hydrophilic and anti - fouling surfaces. The study has demonstrated that these materials have the potential to become the next generation of coatings to inhibit non - specific protein binding. It has also identified new questions to be answered and initiated further exploration along diverse research lines. Currently, neutron scattering data analysis and modelling are in progress in order to get deeper understanding hydration of the studied four-charge molecules. Furthermore, development of functional coatings bearing the four-charge molecules as functional groups is underway to get a strong experimental evidence in support of the formation of protein-resistant hydration layers.

\section{Acknowledgements}

Authors thank EPSRC for financial support through the grant EP/S002669/1. 


\section{References}

[1] I. Banerjee, R.C. Pangule, R.S. Kane, Antifouling coatings: recent developments in the design of surfaces that prevent fouling by proteins, bacteria, and marine organisms, Adv. Mater., 23 (2011) 690718.

[2] C. Blaszykowski, S. Sheikh, M. Thompson, Surface chemistry to minimize fouling from blood-based fluids, Chemical Society Reviews, 41 (2012) 5599-5612.

[3] M. Karlsson, J. Ekeroth, H. Elwing, U. Carlsson, Reduction of irreversible protein adsorption on solid surfaces by protein engineering for increased stability, Journal of Biological Chemistry, 280 (2005) 25558-25564.

[4] K. Nakanishi, T. Sakiyama, K. Imamura, On the adsorption of proteins on solid surfaces, a common but very complicated phenomenon, J. Biosci. Bioeng., 91 (2001) 233-244.

[5] J.A. Callow, M.E. Callow, Trends in the development of environmentally friendly fouling-resistant marine coatings, Nat Commun, 2 (2011) 1-10.

[6] C. Wen, Surface coating and modification of metallic biomaterials Woodhead Publishing series in biomaterials; number 94 Cambridge : Woodhead Publishing, 2015.

[7] E. Ostuni, R.G. Chapman, M.N. Liang, G. Meluleni, G. Pier, D.E. Ingber, G.M. Whitesides, Selfassembled monolayers that resist the adsorption of proteins and the adhesion of bacterial and mammalian cells, Langmuir, 17 (2001) 6336-6343.

[8] S.F. Chen, L.Y. Li, C. Zhao, J. Zheng, Surface hydration: Principles and applications toward lowfouling/nonfouling biomaterials, Polymer, 51 (2010) 5283-5293.

[9] G. Cheng, G.Z. Li, H. Xue, S.F. Chen, J.D. Bryers, S.Y. Jiang, Zwitterionic carboxybetaine polymer surfaces and their resistance to long-term biofilm formation, Biomaterials, 30 (2009) 5234-5240.

[10] S.F. Chen, J. Zheng, L.Y. Li, S.Y. Jiang, Strong resistance of phosphorylcholine self-assembled monolayers to protein adsorption: Insights into nonfouling properties of zwitterionic materials, Journal of the American Chemical Society, 127 (2005) 14473-14478.

[11] Y. Chen, S.C. Luo, Synergistic Effects of Ions and Surface Potentials on Antifouling Poly(3,4ethylenedioxythiophene): Comparison of Oligo(Ethylene Glycol) and Phosphorylcholine, Langmuir, 35 (2019) 1199-1210.

[12] Z. Zhang, H. Vaisocherova, G. Cheng, W. Yang, H. Xue, S.Y. Jiang, Nonfouling Behavior of Polycarboxybetaine-Grafted Surfaces: Structural and Environmental Effects, Biomacromolecules, 9 (2008) 2686-2692.

[13] G. Cheng, Z. Zhang, S.F. Chen, J.D. Bryers, S.Y. Jiang, Inhibition of bacterial adhesion and biofilm formation on zwitterionic surfaces, Biomaterials, 28 (2007) 4192-4199.

[14] D. Nagasawa, T. Azuma, H. Noguchi, K. Uosaki, M. Takai, Role of Interfacial Water in Protein Adsorption onto Polymer Brushes as Studied by SFG Spectroscopy and QCM, J. Phys. Chem. C, 119 (2015) 17193-17201.

[15] A.J. Keefe, S.Y. Jiang, Poly(zwitterionic)protein conjugates offer increased stability without sacrificing binding affinity or bioactivity, Nature chemistry, 4 (2012) 60-64.

[16] R.G. Chapman, E. Ostuni, S. Takayama, R.E. Holmlin, L. Yan, G.M. Whitesides, Surveying for surfaces that resist the adsorption of proteins, Journal of the American Chemical Society, 122 (2000) 8303-8304.

[17] R.S. Kane, P. Deschatelets, G.M. Whitesides, Kosmotropes form the basis of protein-resistant surfaces, Langmuir, 19 (2003) 2388-2391.

[18] R.E. Holmlin, X.X. Chen, R.G. Chapman, S. Takayama, G.M. Whitesides, Zwitterionic SAMs that resist nonspecific adsorption of protein from aqueous buffer, Langmuir, 17 (2001) 2841-2850.

[19] M. Blesic, B.F. Gilmore, J.D. Holbrey, J. Jacquemin, G. Level, P. Nockemann, L. Stella, An introduction to zwitterionic salts, Green Chemistry, 19 (2017) 4007-4011.

[20] G. Level, M.V. Fadul, M. Blesic, Solubility-Modifying Power of Zwitterionic Salts, Chemphyschem, 19 (2018) 575-580. 
[21] A.M. Ferreira, H. Passos, A. Okafuji, M.G. Freire, J.A.P. Coutinho, H. Ohno, Designing the thermal behaviour of aqueous biphasic systems composed of ammonium-based zwitterions, Green Chemistry, 19 (2017) 4012-4016.

[22] J.A. Rackers, Z. Wang, C. Lu, M.L. Laury, L. Lagardere, M.J. Schnieders, J.P. Piquemal, P.Y. Ren, J.W. Ponder, Tinker 8: Software Tools for Molecular Design, J. Chem. Theory Comput., 14 (2018) 52735289.

[23] Michael R. J. Dack, Solutions and Solubilities, Part 1, Techniques of Chemistry, Wiley-Interscience, New York, 1975.

[24] F. Hernandez-Luis, R. Rodriguez-Raposo, H.R. Galleguillos, J.W. Morales, Solubility of Sodium Halides in Aqueous Mixtures with epsilon-Increasing Cosolvents: Formamide, N-Methylformamide, and N-Methylacetamide at $298.15 \mathrm{~K}$, Ind. Eng. Chem. Res., 55 (2016) 812-819.

[25] K.D. Collins, Ion hydration: Implications for cellular function, polyelectrolytes, and protein crystallization, Biophys. Chem., 119 (2006) 271-281.

[26] K.D. Collins, Charge density-dependent strength of hydration and biological structure, Biophys. J., 72 (1997) 65-76.

[27] K.D. Collins, lons from the Hofmeister series and osmolytes: effects on proteins in solution and in the crystallization process, Methods, 34 (2004) 300-311.

[28] J.O. Bockris, P.P.S. Saluja, Time-Dependent Solvation Number for lons in Solution, J. Electrochem. Soc., 119 (1972) 1060-1061.

[29] A.K. Adya, G.W. Neilson, Structure of a $50 \mathrm{Mol} \mathrm{Kg-1} \mathrm{Aqueous-Solution} \mathrm{of} \mathrm{Ammonium-Nitrate} \mathrm{at}$ 373-K by the Isotopic Difference Method of Neutron-Diffraction, J. Chem. Soc.-Faraday Trans., 87 (1991) 279-286.

[30] J.O. Bockris, lonic Solvation, Quarterly Reviews, Chemical Society, (1949) 173-180.

[31] J.F. Hinton, E.S. Amis, Solvation numbers of ions, Chem. Rev., 71 (1971) 627-674.

[32] R.A. Horne, Water and Aqueous Solutions. Structure, Thermodynamics, and Transport Processes., Wiley-Interscience, New York, 1972.

[33] O. Redlich, D.M. Mayer, The Molal Volumes of Electrolytes, Chem. Rev., 64 (1964) 221-227.

[34] Y. Marcus, Electrostriction in Electrolyte Solutions, Chem. Rev., 111 (2011) 2761-2783.

[35] O. Tirosh, Y. Barenholz, J. Katzhendler, A. Priev, Hydration of polyethylene glycol-grafted liposomes, Biophys. J., 74 (1998) 1371-1379.

[36] F.J. Millero, A. Lo Surdo, C. Shin, The Apparent Molal Volumes and Adiabatic Copresssibilities of Amino Acid at $25^{\circ} \mathrm{C}$, The Journal of Phyisical Chemistry, 82 (1978) 784-792.

[37] D. Tran, J.P. Hunt, S. Wherland, Molar Volumes of Coordination-Complexes in Nonaqueous Solution - Correlation with Computed Vanderwaals Volumes, Crystal Unit-Cell Volumes, and Charge, Inorganic Chemistry, 31 (1992) 2460-2464.

[38] J. Padova, Ion-Solvent Interaction. II. Partial Molar Volume and Electrostriction: a Thermodynamic Approach, The Journal of Chemical Physics, 39 (1963) 1552-1557.

[39] F.J. Millero, G.K. Ward, F.K. Lepple, E.V. Hoff, Isothermal Compressibility of Aqueous SodiumChloride, Magnesium Chloride, Sodium-Sulfate, and Magnesium-Sulfate Solutions from 0 to 45 Degrees at 1 Atm, Journal of Physical Chemistry, 78 (1974) 1636-1643.

[40] K.D. Collins, M.W. Washabaugh, The Hofmeister effect and the behaviour of water at interfaces, Q Rev Biophys, 18 (1985) 323-422.

[41] M.H. Abraham, J. Liszi, E. Papp, Calculations on Ionic Solvation .6. Structure-Making and StructureBreaking Effects of Alkali-Halide Ions from Electrostatic Entropies of Solvation - Correlation with Viscosity B-Coefficients, Nuclear Magnetic-Resonance B'-Coefficients and Partial Molal Volumes, Journal of the Chemical Society-Faraday Transactions I, 78 (1982) 197-211.

[42] G. Jones, D. Malcolm, The viscosity of aqueous solutions of strong electrolytes with special reference to barium chloride, J. Am. Chem. Soc., 51 (1929) 2950-2964.

[43] H.D.B. Jenkins, Y. Marcus, Viscosity B-coefficients of ions in solution, Chem. Rev., 95 (1995) 26952724. 
[44] H. Zhao, Are ionic liquids kosmotropic or chaotropic? An evaluation of available thermodynamic parameters for quantifying the ion kosmotropicity of ionic liquids, Journal of Chemical Technology and Biotechnology, 81 (2006) 877-891.

[45] V.V. Yaminsky, E.A. Vogler, Hydrophobic hydration, Current Opinion in Colloid \& Interface Science, 6 (2001) 342-349.

[46] R. Tomas, A. Tot, J. Kuhar, M. Bester-Rogac, Interactions in aqueous solutions of imidazolium chloride ionic liquids $C(n)$ mim $C l(n=0,1,2,4,6,8)$ from volumetric properties, viscosity B-coefficients and molecular dynamics simulations, Journal of Molecular Liquids, 254 (2018) 267-271.

[47] J. Mills, G. Level, C. Mangwandi, M. Blesic, Aqueous biphasic systems formed in (zwitterionic salt plus inorganic salt) mixtures, Pure Appl. Chem., 91 (2019) 1351-1360.

[48] P. Jungwirth, D.J. Tobias, Molecular structure of salt solutions: A new view of the interface with implications for heterogeneous atmospheric chemistry, Journal of Physical Chemistry B, 105 (2001) 10468-10472.

[49] N.L. Jarvis, M.A. Scheiman, Surface potentials of aqueous electrolyte solutions, Journal of Physical Chemistry, 72 (1968) 74-78.

[50] R. Breslow, T. Guo, Surface tension measurements show that chaotropic salting-in denaturants are not just water-structure breakers, Proc Natl Acad Sci U S A, 87 (1990) 167-169.

[51] A. Renoncourt, N. Vlachy, P. Bauduin, M. Drechsler, D. Touraud, J.M. Verbavatz, M. Dubois, W. Kunz, B.W. Ninham, Specific alkali cation effects in the transition from micelles to vesicles through salt addition, Langmuir, 23 (2007) 2376-2381.

[52] N. Hedin, I. Furo, P.O. Eriksson, Fast diffusion of the $\mathrm{Cl}$ - ion in the headgroup region of an oppositely charged micelle. A Cl-35 NMR spin relaxation study, Journal of Physical Chemistry B, 104 (2000) 8544-8547.

[53] M. Blesic, M.H. Marques, N.V. Plechkova, K.R. Seddon, L.P.N. Rebelo, A. Lopes, Self-aggregation of ionic liquids: micelle formation in aqueous solution, Green Chemistry, 9 (2007) 481-490.

[54] M. Sagisaka, T. Saito, A. Yoshizawa, S.E. Rogers, F. Guittard, C. Hill, J. Eastoe, M. Blesic, Water-inCO2 Microemulsions Stabilized by Fluorinated Cation-Anion Surfactant Pairs, Langmuir, 35 (2019) 3445-3454.

[55] S. Miller, J. Janin, A.M. Lesk, C. Chothia, Interior and surface of monomeric proteins, J Mol Biol, 196 (1987) 641-656.

[56] L.R. Miesfeld, M.M. McEvoy, Biochemistry, W. W. Norton \& Company, New York, 2017.

[57] G. Gros, B.A. Wittenberg, T. Jue, Myoglobin's old and new clothes: from molecular structure to function in living cells, Journal of Experimental Biology, 213 (2010) 2713-2725.

[58] Y. Moriyama, H. Sasaoka, T. Ichiyanagi, K. Takeda, Secondary structural changes of metmyoglobin and apomyoglobin in anionic and cationic surfactant solutions: effect of the hydrophobic chain length of the surfactants on the structural changes, J Protein Chem, 11 (1992) 583-588.

[59] T. Arakawa, S.N. Timasheff, Mechanism of protein salting in and salting out by divalent cation salts: balance between hydration and salt binding, Biochemistry, 23 (1984) 5912-5923.

[60] C.M. Jones, An introduction to research in protein folding for undergraduates, Journal of Chemical Education, 74 (1997) 1306-1310.

[61] A. Safavi, F. Farjami, Hydrogen peroxide biosensor based on a myoglobin/hydrophilic room temperature ionic liquid film, Analytical Biochemistry, 402 (2010) 20-25.

[62] A. Kumar, P. Venkatesu, A comparative study of myoglobin stability in the presence of Hofmeister anions of ionic liquids and ionic salts, Process Biochemistry, 49 (2014) 2158-2169.

[63] J.C. Hower, M.T. Bernards, S.F. Chen, H.K. Tsao, Y.J. Sheng, S.Y. Jiang, Hydration of "Nonfouling" Functional Groups, Journal of Physical Chemistry B, 113 (2009) 197-201.

[64] Q. Shao, Y. He, A.D. White, S.Y. Jiang, Difference in Hydration between Carboxybetaine and Sulfobetaine, Journal of Physical Chemistry B, 114 (2010) 16625-16631. 